\title{
Proteomic analysis of the inhibitory effect of epigallocatechin gallate on lipid accumulation in human HepG2 cells
}

Zhonghua Liu' ${ }^{1,2,3 \dagger}$, Qin Li ${ }^{2,3+}$, Jianan Huang ${ }^{2}$, Qionglin Liang ${ }^{1}$, Yujun Yan ${ }^{3}$, Haiyan Lin ${ }^{3}$, Wenjun Xiao ${ }^{3}$, Yong Lin ${ }^{3}$, Sheng Zhang ${ }^{3}$, Bin $\operatorname{Tan}^{3}$ and Guoan Luo ${ }^{1 *}$

\begin{abstract}
Background: (-)-Epigallocatechin-3-gallate (EGCG), the most abundant catechin found in green tea, effectively reduces body weight and tissue and blood lipid accumulation. To explore the mechanism by which EGCG inhibits cellular lipid accumulation in free fatty acid (FFA) induced HepG2 cell culture, we investigated the proteome change of FFA-induced HepG2 cells exposed to EGCG using two-dimensional gel electrophoresis and mass spectrometry.

Results: In this study, 36 protein spots showed a significant change in intensity by more than 1.5-fold from the control group to the FFA group and from the FFA group to the FFA + EGCG group. Among them, 24 spots were excised from gels and identified by LC-MS/MS. In total, 18 proteins were successfully identified. All identified proteins were involved in lipid metabolism, glycometabolism, antioxidant defense, respiration, cytoskeleton organization, signal transduction, DNA repair, mRNA processing, iron storage, or were chaperone proteins. This indicated that these physiological processes may play roles in the mechanism of inhibition of lipid accumulation by EGCG in FFA-induced HepG2 cells. Western blotting analysis was used to verify the expression levels of differentially expressed proteins, which agree with the proteomic results.

Conclusions: From the proteomic analysis, we hypothesized that EGCG reduced cellular lipid accumulation in FFA-induced HepG2 cells through the activation of AMP-activated protein kinase (AMPK) resulting from the generation of reactive oxygen species (ROS). The induction of ROS may be a result of EGCG regulation of the antioxidant defense system. Activation of AMPK shifted some FFA toward oxidation, away from lipid and triglyceride storage, and suppressed hepatic gluconeogenesis. The findings of this study improve our understanding of the molecular mechanisms of inhibition of lipid accumulation by EGCG in HepG2 cells.
\end{abstract}

Keywords: Proteomics, (-)-Epigallocatechin-3-gallate, HepG2 cells, Lipid accumulation

\section{Background}

Nonalcoholic fatty liver disease (NAFLD), defined by excessive liver fat accumulation related to metabolic syndrome, is a leading cause of progressive liver disease. NAFLD is a clinicopathological term that encompasses a disease spectrum ranging from simple lipid accumulation in hepatocytes (hepatic steatosis) to hepatic steatosis with inflammation (steatohepatitis), fibrosis, and cirrhosis [1].

\footnotetext{
*Correspondence: luoga@mail.tsinghua.edu.cn

${ }^{\dagger}$ Equal contributors

'Department of Chemistry, Tsinghua University and Key Laboratory of Biological Organic Phosphorus and Chemical Biology, Ministry of Education, Beijing 100084, China

Full list of author information is available at the end of the article
}

Excess hepatic lipid accumulation is associated with nutritional factors, drugs, and multiple genetic defects in energy metabolism.

Green tea is widely consumed throughout the world, especially in East Asian countries. Research indicates that green tea is beneficial to health and many components of tea have specific health-promoting effects [2,3]. Studies have suggested that (-)-epigallocatechin-3-gallate (EGCG), the most abundant catechin found in green tea, could effectively reduce body weight and tissue and blood fat accumulation $[4,5]$. In high-fat-fed mice, EGCG decreased liver weight, liver triglycerides, plasma alanine aminotransferase concentrations, lipid accumulation in hepatocytes

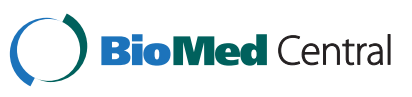


[6], and reduced the development of experimental nonalcoholic steatohepatitis through its effect on lipid metabolism [7]. EGCG treatment could effectively reduce fatty liver incidence, liver damage, and liver triglyceride levels in Male C57BL/6J mice fed with a high-fat, Western-style diet [8]. These beneficial effects of EGCG are associated with decreased lipid absorption and reduced levels of inflammatory cytokines. Previous studies have suggested that EGCG and green tea might modulate expression of lipid metabolism-related genes. EGCG treatment up-regulated several genes related to fat oxidation and thermogenesis, including liver acyl-CoA oxidase (AOX), medium-chain acyl-CoA dehydrogenase (MCAD), muscle uncoupling protein-2 (UCP2) and uncoupling protein-3 (UCP3), and fatty acid translocase [9-11]. Moreover, EGCG treatment down-regulated several genes related to fatty acid synthesis and storage in the liver and white adipose tissue, including acetyl-CoA carboxylase (ACC), fatty acid synthase (FAS), malic enzyme (ME), glucose-6-phosphate dehydrogenase (G6PDH), glycerol-3 -phosphate dehydrogenase (G3PDH), and stearoyl-CoA desaturase-1 (SCD1) [12-15].

Despite the amount of work on EGCG, there is little proteomic information available on EGCG inhibiting lipid accumulation in free fatty acid (FFA) induced HepG2 cells. To investigate the inhibitory effect of EGCG on FFAinduced lipid accumulation, HepG2 cells were exposed to FFA co-treated with $50 \mu \mathrm{M}$ EGCG. The proteome changes of FFA-induced HepG2 cells were investigated by twodimensional gel electrophoresis (2-DE) combined with matrix-assisted laser desorption ionization time-of-flight mass spectrometry (MALDI-TOF/TOF MS). The objective of this study was to obtain an improved understanding of the mechanism by which EGCG inhibits lipid accumulation in FFA-induced HepG2 cells.

\section{Results \\ Effect of EGCG on FFA-induced intracellular lipid accumulation in HepG2 cells}

Fatty liver results from an imbalance between lipid availability and lipid metabolism. Palmitic and oleic acids are the most abundant FFA in liver triglycerides in both normal subjects and patients with NAFLD [16]. Exposure of HepG2 cells to exogenous FFA leads to significant intracellular lipid accumulation [17]. HepG2 cells loaded with $1 \mathrm{mM}$ FFA mixture (oleic acid [OA] and palmitic acid [PA], 2:1) mimics benign chronic steatosis in humans [18]. As shown in Figure 1A, the intracellular lipid content could be significantly lowered by treatment with $50 \mu \mathrm{M}$ EGCG. This suggested that EGCG could significantly inhibit FFA-induced intracellular lipid accumulation in HepG2 cells. This result was also confirmed by the quantification of intracellular triglycerides and cholesterol contents. In Figure 1B, EGCG treatment showed significantly lower triglyceride levels $(p \leq 0.05)$. The content of cholesterol was also lowered but not significantly. The effects of EGCG on FFA-stimulated HepG2 cell viability were examined by MTT assay and annexin V staining. The results showed that cell viability was not compromised by $50 \mu \mathrm{M}$ EGCG treatment after $24 \mathrm{~h}$ of exposure (Figure $1 \mathrm{C}$ and $\mathrm{D})$.

\section{Change in protein abundance in the three groups}

To explore the inhibitory effect of EGCG on FFA-induced lipid accumulation in HepG2 cells, the proteomes of the control, FFA-induced (FFA) and FFA-induced co-treated with $50 \mu \mathrm{M}$ EGCG groups (FFA + EGCG) were analyzed by $2-\mathrm{DE}$ (Figure 2). Among the tested samples, more than 800 protein spots were reproducibly detected with PDQuest 8.0.1 software on Coomassie Brilliant Blue (CBB) G-250-stained gels. The control and FFA + EGCG groups had 142 and 151 protein spots that showed a significant change in expression level in when compared with the FFA group, respectively. Moreover, 36 protein spots showed a significant change in intensity by more than 1.5fold from the control group to the FFA group and from the FFA group to the FFA + EGCG group. Among them, 24 spots that changed at least 2.0-fold were excised from gels and identified by MALDI-TOF/TOF MS. In total, 18 protein spots were successfully identified and the results are summarized in Table 1. The functions of the differentially expressed proteins were obtained using their protein accession numbers from the SwissProt/NCBI protein function summary. All identified proteins in this study were involved in multiple functional groups (Table 1), including lipid metabolism, glycometabolism, antioxidant defense, respiration, cytoskeleton organization, signal transduction, DNA repair, mRNA processing, and iron storage, or were chaperone proteins.

\section{Validation of differentially expressed proteins by western blotting}

Western blotting analysis was performed in triplicate to confirm the differentially expression proteins found in the proteomic analysis. FFA-induced HepG2 cells were treated with $50 \mu \mathrm{M}$ EGCG for $24 \mathrm{~h}$. Equal amounts of total proteins from different treated cells were used for western blotting analysis. The results (Figure 3) suggested that the expressed levels of peroxiredoxin-6 (Prdx6) and galactokinase (GALK) were significantly lower $(p \leq 0.05)$ and succinate dehydrogenase flavoprotein subunit (SDHA) was significantly higher $(p \leq 0.05)$ in the FFA + EGCG group compared with the FFA group. Therefore, the western blotting results agree with the proteomic results.

\section{Discussion}

Lipid accumulation is the main cause of NAFLD, which results in fatty tissue degeneration [1,19]. This lipid 

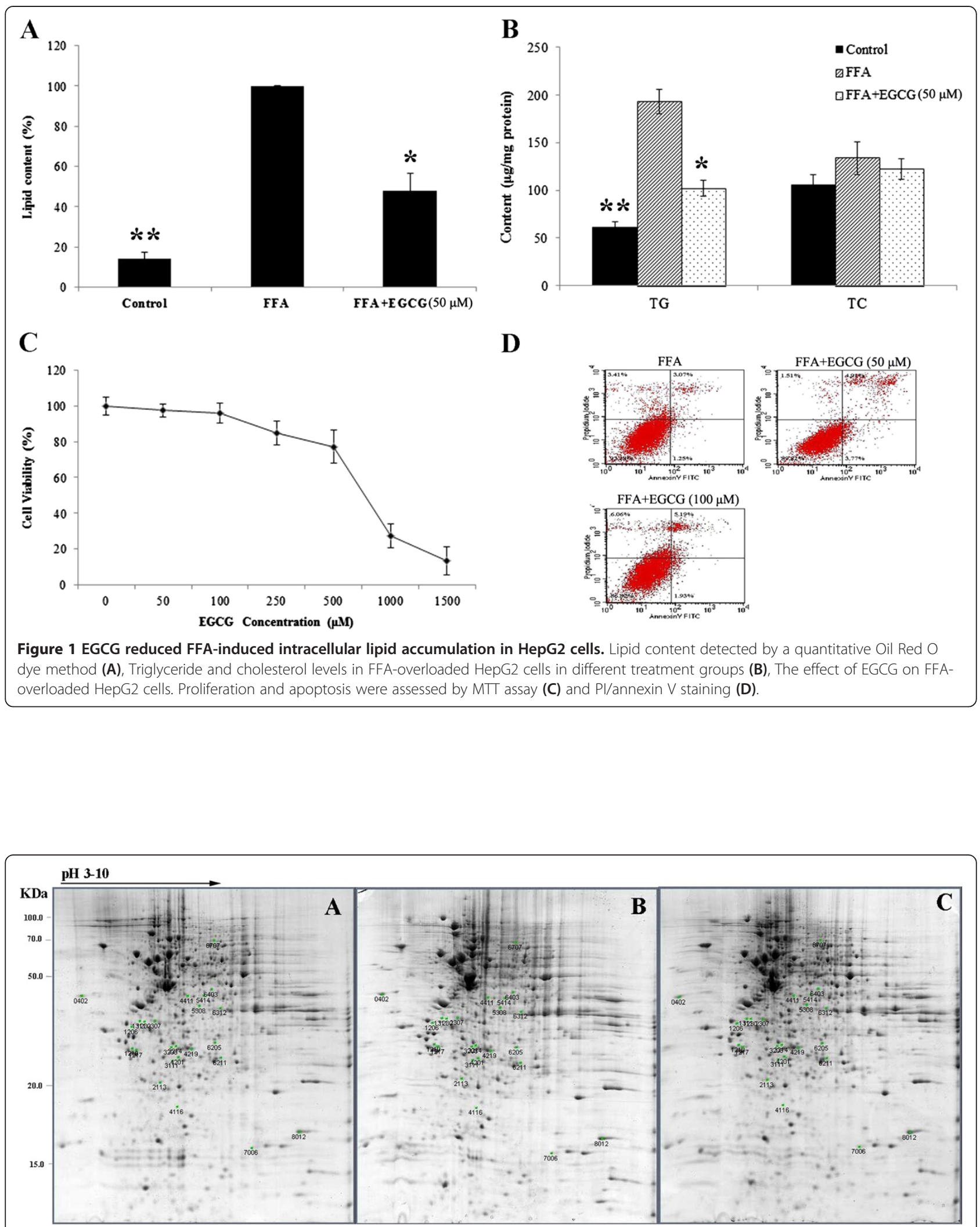

Figure 2 Comparison of 2-D electrophoresis analysis of the proteins expressed in FFA-stimulated HepG2 cells derived from different treatment groups. Control (A), FFA (B), FFA + EGCG (C). Proteins that exhibited a significant expression change $(\geq 1.5$-fold, $p \leq 0.05)$ from the control group to FFA group while from the FFA group to FFA + EGCG group are labeled in the figures. 
Table 1 Differentially expressed proteins identified by MS or MS/MS

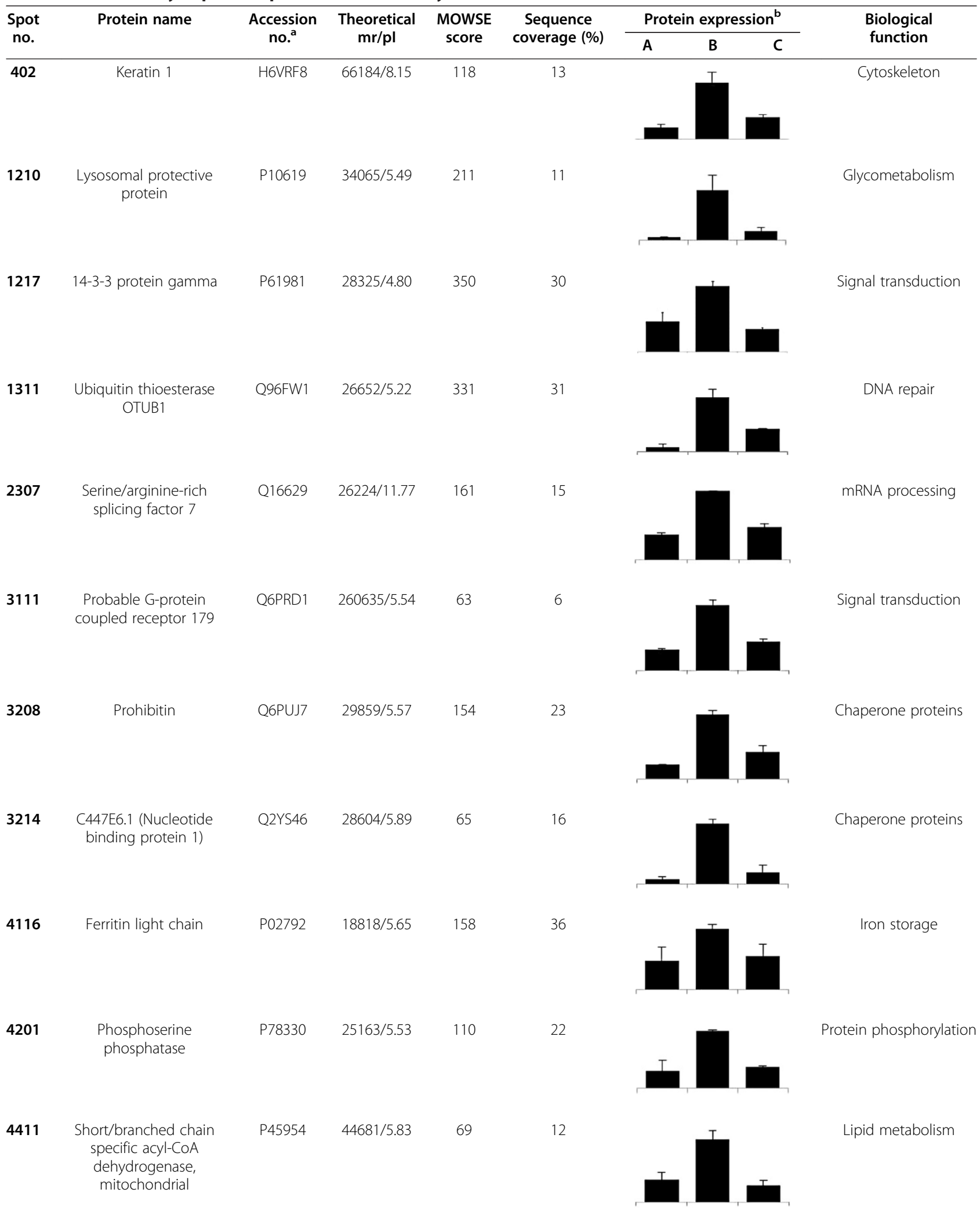


Table 1 Differentially expressed proteins identified by MS or MS/MS (Continued)

\begin{tabular}{|c|c|c|c|c|c|c|}
\hline 5308 & $\begin{array}{l}\text { Serine/threonine-protein } \\
\text { phosphatase PP1-alpha } \\
\text { catalytic subunit }\end{array}$ & P62136 & $38229 / 5.94$ & 239 & 29 & Protein phosphorylation \\
\hline 5414 & Galactokinase & P51570 & $42702 / 6.04$ & 131 & 14 & Glycometabolism \\
\hline 6205 & Peroxiredoxin-6 & P30041 & $25133 / 6.60$ & 70 & 18 & Antioxidant defense \\
\hline 6211 & $\begin{array}{l}\text { Platelet-activating } \\
\text { factor acetylhydrolase } \\
\text { IB subunit gamma }\end{array}$ & Q15102 & $25832 / 6.33$ & 136 & 26 & Lipid metabolism \\
\hline 6403 & Septin-2 & Q15019 & $41689 / 6.15$ & 123 & 21 & Cytoskeleton \\
\hline 6707 & $\begin{array}{l}\text { Succinate dehydrogenase } \\
\text { [ubiquinone] flavoprotein } \\
\text { subunit, mitochondrial }\end{array}$ & P31040 & $73672 / 7.06$ & 170 & 25 & Respiration \\
\hline 8012 & Cofilin-1 & P23528 & $18719 / 8.22$ & 128 & 31 & Signal transduction \\
\hline
\end{tabular}

\footnotetext{
${ }^{a}$ SwissProt accession number.

${ }^{b}$ A: control group. B: FFA group. C: FFA + EGCG $(50 \mu \mathrm{M})$ group.
}

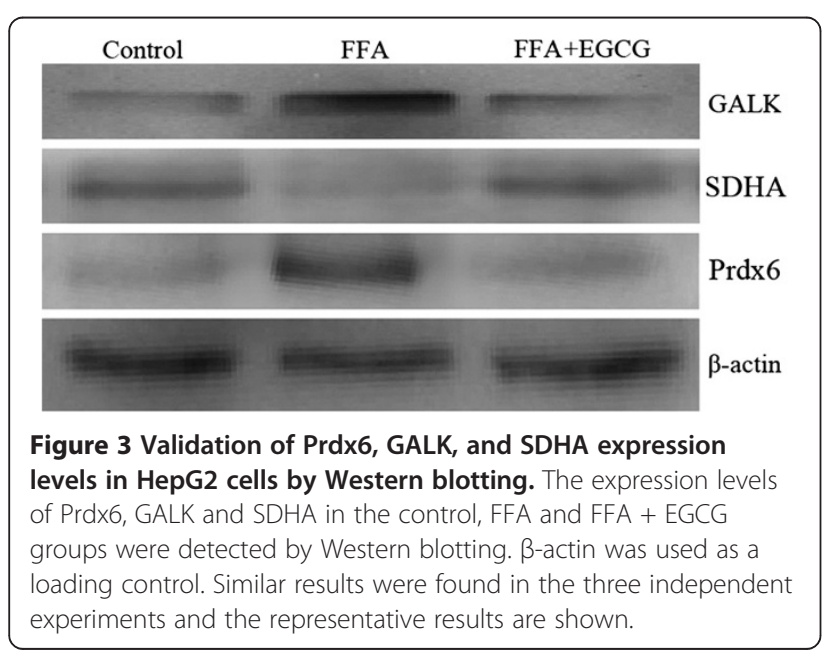

accumulation in hepatocytes results from an imbalance between lipogenesis and lipolysis metabolism causing eventual lipoperoxidative stress and hepatic injury [20]. Previous studies suggest that the inhibitory action of EGCG on lipid accumulation is mediated via the AMPactivated protein kinase (AMPK) pathway [21-23]. Activation of AMPK can induce ATP generation through glycolysis and $\beta$-oxidation, and suppress fatty acid and cholesterol syntheses, and gluconeogenesis [24]. However, the inhibitory effect of EGCG on FFA-induced intracellular lipid accumulation at the proteomic level has not been investigated. In this study, we reported a comprehensive proteome, which deduced the target genes of EGCG as well as its inhibitory effect on lipid accumulation in FFA-induced HepG2 cells. Eighteen differentially expressed proteins were successfully identified. These proteins are involved in lipid metabolism, glycometabolism, antioxidant defense, respiration, cytoskeleton organization, signal transduction, DNA repair, 
mRNA processing, and iron storage, or are chaperone proteins. This indicates that these physiological processes may play a role in the mechanism by which EGCG inhibits cellular lipid accumulation in FFA-induced HepG2 cells.

\section{Proteins involved in redox regulation and energy metabolism}

After treatment with EGCG, two differentially expressed proteins related to redox and respiratory regulation were identified in HepG2 cells. Prdx6 is the sixth mammalian member of the peroxiredoxin family, which has an important role in antioxidant defense $[25,26]$. Several studies reported that an increase in reactive oxygen species (ROS) could lead to AMPK activation [27,28]. EGCG significantly induced generation of ROS and reduced glutathione (GSH) in cells [21-23]. AMPK is thought to be a novel target for the treatment of obesity and type II diabetes [29]. Activation of AMPK in liver and skeletal muscle leads to the stimulation of fatty acid oxidation and inhibition of lipogenesis, glucose production and protein synthesis [30,31]. However, these effects could be eliminated by ROS scavenger, $\mathrm{N}$-acetylcysteine, treatment $[22,23,28]$. In our proteomic experiment, Prdx6 was down-regulated by EGCG treatment. This may be a reason for the increasing ROS levels that lead to AMPK activation, preventing lipid accumulation in cells. Succinate dehydrogenase (SDH or ubiquinone) is an enzyme that controls the transcription of metabolism-related genes in mitochondria and promotes metabolism of glucose and lipids [32,33]. SDH is related to oxidative metabolism and is an indicator of oxidative capacity in cells [34]. Prior studies have found that a reduction in oxidative enzymes is correlated with a reduced capacity for lipid oxidation and increased risk for obesity [35,36]. The mRNA expression levels of $\mathrm{SDH}$ are reduced in mice with type II diabetes mellitus and obesity [37]. Several studies have also shown that weight loss and exercise could result in a significant increase in SDH activity $[38,39]$. Our proteomic analysis showed that SDHA was up-regulated by EGCG treatment in FFA-induced HepG2 cells, indicating that EGCG increased lipid oxidation by enhancing energy expenditure and fat oxidation in the mitochondria of HepG2 cells.

\section{Proteins involved in lipid metabolism}

Proteins involved in lipid metabolism were changed significantly by EGCG treatment in HepG2 cells. Plateletactivating factor acetylhydrolase (PAFAH), a unique member of the phospholipase A2 superfamily, is characterized by its ability to specifically hydrolyze plateletactivating factor (PAF) and glycerophospholipids [40]. PAF is a potent pro-inflammatory phospholipid that activates cells involved in inflammation and stimulates ROS generation [41-43]. Down-regulation of platelet- activating factor acetylhydrolase IB subunit gamma (PAFAH1B3) by EGCG treatment might lead to an increase of PAF, which could stimulate the generation of ROS and activating AMPK in HepG2 cells. Short/ branched-chain acyl-CoA dehydrogenase (SBCAD) catalyzes the first step in the mitochondrial $\beta$-oxidation of L-2-methylated short acyl-CoA compounds [44]. SBCAD deficiency is characterized by accumulation of 2methylbutyrylglycine (2MBG), which induced an increase of lipid oxidation and a decrease of antioxidant defenses (decreased GSH) in rat [45]. In our proteomic experiment, SBCAD was down-regulated in the EGCG-treated group. This might result in a decrease of antioxidant defense and a high level of cellular ROS, which could activate AMPK to prevent cellular lipid accumulation.

\section{Proteins involved in glycometabolism}

Two proteins involved in glycometabolism were downregulated by EGCG treatment. GALK catalyzes the phosphorylation of $\alpha$-galactose to galactose-1-phosphate in the second step of the Leloir pathway, a metabolic pathway found in most organisms for the catabolism of $\beta$-galactose to glucose-1-phosphate [46]. Glucose-1-phosphate could be metabolized to glucose-6-phosphate providing substrate for the pentose phosphate pathway, which generates ribose-5-phosphate and NADPH for the biosynthesis of fatty acids and sterols [47]. A study reported that unsaturated fatty acids could increase the activation of galactokinase and galactose-1-phosphate uridyltransferase, and stimulate sterol biosynthesis from galactose [48]. Downregulation of galactokinase reduces ribose-5-phosphate and NADPH from the pentose phosphate pathway, resulting in a reduction of the biosynthesis of fatty acids and sterols in FFA-induced HepG2 cells. Lysosomal protective protein (PPCA) appears to be essential for the activity of $\beta$-galactosidase, which catalyzes the hydrolysis of $\beta$-galactosides into $\beta$-galactose and glucoside. PPCA associates with $\beta$-galactosidase and exerts a protective function necessary for its stability and activity [49]. Downregulation of PPCA could reduce the activity of $\beta$ galactosides and decrease $\beta$-galactose for the Leloir pathway, inhibiting the biosynthesis of fatty acids and sterols from galactose $[47,48]$.

\section{Proteins involved in biological regulation and signal transduction}

Some proteins involved in biological regulation and signal transduction were also identified in HepG2 cells, including serine/threonine protein phosphatase-alpha catalytic subunit (PP-1A), phosphoserine phosphatase (PSP), 14-3-3 protein gamma and prohibitin (PHB). PP$1 \mathrm{~A}$ and PSP belong to the phosphoprotein phosphatase family, which remove the phosphate from the serine or threonine residues of phosphoproteins [50]. Previous 
study reported that a glucose-induced activation of the transcription of the FAS gene was markedly reduced by okadaic acid, an inhibitor of protein serine/threonine phosphatases 1 (PP1) and PP2A, and by AICAR, a cellpermeable activator of the AMPK [51]. These results indicated that the reduction of the FAS gene involves a phosphorylation/dephosphorylation mechanism and AMPK activation. Therefore, down-regulation of PP-1A and PSP might indicate an inhibition of lipid biosynthesis and an activation of AMPK in HepG2 cells by EGCG treatment. 14-3-3 protein gamma belongs to the 14-3-3 protein family, which has the ability to bind many functionally diverse signaling proteins, including kinases, phosphatases, and transmembrane receptors [52,53]. The transcriptional co-activator transducer of regulated CREB activity 2 (TORC2) is a pivotal component of gluconeogenesis [54]. Phosphorylated TORC2 is sequestered in the cytoplasm via a phosphorylation-dependent interaction with 14-3-3 proteins and degraded by $26 \mathrm{~S}$ proteasome to inhibit the gluconeogenic program [55]. A report suggested that inhibition of enhanced gluconeogenesis induced by high-fat and high-fructose diet could improve lipid metabolism and hepatic steatosis in mice [56]. Thus, up-regulation of 14-3-3 protein by EGCG treatment in FFA-induced HepG2 cells might indicate that the hepatic steatosis induced by overloaded FFA was improved through inhibition of gluconeogenesis. PHB comprise two evolutionarily conserved proteins, prohibitin-1 (PHB1) and prohibitin-2 (PHB2), and are present in a high molecular-weight complex in the inner membrane of mitochondria [57,58]. PHB1 decreased insulin-stimulated oxidation of glucose and fatty acids, implying that PHB1 may play a role in promoting fat accumulation [59]. A microarray analysis showed that the expression levels of PHB were increased during 3T3-L1 cell adipogenesis [60]. Several studies showed that depletion of PHB1 or PHB2 in C. elegans or 3T3-L1 cells could significantly decrease adipose accumulation and adipogenesis [61]. In the current study, EGCG decreased the expression of $\mathrm{PHB}$, which might be one of the reasons that EGCG could inhibit lipid accumulation in FFA-induced HepG2 cells.

\section{Conclusions}

In summary, this study demonstrates that EGCG can significantly suppress the lipid accumulation in FFA-induced HepG2 cells. Using a proteomic approach, we identified 18 differentially expressed proteins responsive to EGCG treatment involving multiple cellular processes. From the proteomic analysis, we supposed that EGCG reduced cellular lipid accumulation in FFA-induced HepG2 cells through the activation of AMPK resulting from the generation of ROS. The induction of ROS may be because EGCG regulated the antioxidant defense system in HepG2 cells (Figure 4). Activation of AMPK shifted some FFA toward oxidation, away from lipid and triglyceride storage, and suppressed hepatic gluconeogenesis in HepG2 cells. Findings of this study provide information to improve our understanding of the molecular mechanisms of the inhibition of lipid accumulation by EGCG in HepG2 cells.

\section{Methods}

\section{Materials}

All chemicals used were of analytic grade. EGCG was obtained from Sigma (St. Louis, MO, USA), the purity of EGCG was $\geq 95 \%$. Oleic acid and palmitic acid were also obtained from Sigma. Antibodies to $\beta$-actin and Prdx6 were obtained from GeneTex (Irvine, CA, USA). Antibodies to SDHA and GALK were obtained from Abcam (Cambridge, UK).

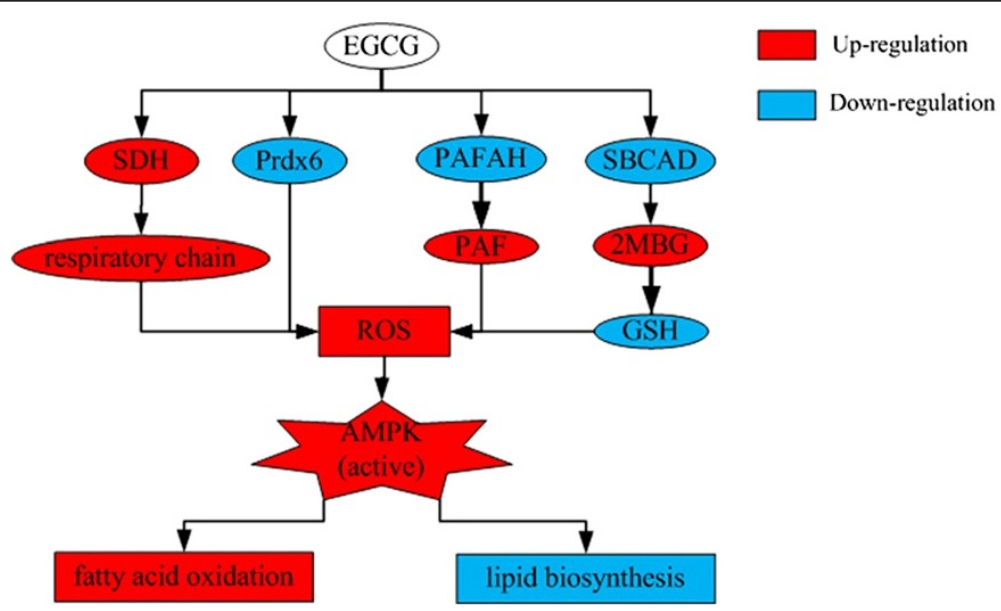

Figure 4 A simple model of the proposed mechanism by which EGCG inhibits lipid accumulation in FFA-induced HepG2 cells. Arrowheads indicate the direct or indirect interactions. The up-regulated proteins are marked with red and the down-regulated proteins are marked with blue. 


\section{Cell culture and EGCG stimulation}

Experiments were approved by the ethics committee of Tsinghua University. HepG2 cells (human liver hepatocellular carcinoma cell line) were obtained from the cell bank of the Type Culture Collection of Chinese Academy of Sciences, and were cultured in DMEM medium (Thermo, South Logan, UT, USA) with $10 \%$ fetal calf serum, $100 \mathrm{U} / \mathrm{mL}$ penicillin, $100 \mu \mathrm{g} / \mathrm{mL}$ streptomycin, and $2 \mathrm{mM} \mathrm{L}$-glutamine and kept at $37^{\circ} \mathrm{C}$ in a humidified atmosphere (Nuaire, Plymouth, MN, USA) with 5\% $\mathrm{CO}_{2}$. To induce fat-overloading, HepG2 cells were exposed to $1 \mathrm{mM}$ of FFA mixture (OA / PA, 2:1) mixed with $1 \%$ FFA-free bovine serum albumin $[17,28,62]$. Stock solutions of $50 \mathrm{mM}$ FFA were prepared as reported previously [63]. When the cells reached 70\% confluence, they were incubated in serum-free medium for $24 \mathrm{~h}$ before treatments. Then, the cells were stimulated with $1 \mathrm{mM}$ FFA and co-treated with EGCG for $24 \mathrm{~h}$.

\section{Cell proliferation and apoptosis assay}

The effect of EGCG on cell proliferation was assessed using MTT assay as previously reported [64]. Briefly, HepG2 cells were plated in 96-well plates $\left(5 \times 10^{3}\right.$ cells/ well) and treated with $1 \mathrm{mM}$ FFA with various concentrations of EGCG for $24 \mathrm{~h}$. Then cells were incubated with $100 \mu \mathrm{L}$ MTT solution $(0.5 \mathrm{mg} / \mathrm{mL}$ MTT in PBS buffer) for $4 \mathrm{~h}$. The absorbance was measured with a Multiskan MK3 (Thermo) at $490 \mathrm{~nm}$. Apoptotic cells were detected using flow cytometry with PI/annexin V staining [64]. Cells were seeded in six-well plates $(4 \times$ $10^{6}$ cells/well) and co-incubated with 0,50 , and $100 \mu \mathrm{M}$ of EGCG and $1 \mathrm{mM}$ FFA for $24 \mathrm{~h}$. After harvesting with $0.25 \%$ trypsin, cells were resuspended with $200 \mu \mathrm{L}$ binding buffer and incubated with $10 \mu \mathrm{L}$ Annexin V-FITC and $5 \mu \mathrm{L}$ PI for $15 \mathrm{~min}$ at room temperature. Sample solutions were adjusted to $500 \mu \mathrm{L}$ using binding buffer and analyzed with a FACScan flow cytometer (Becton Dickinson Biosciences, San Jose, CA, USA) within an hour of sample preparation. The data were analyzed by Modfit3.0 (Verity Software House, Topsham, ME, USA). All treatments were performed in triplicate.

\section{Oil Red $O$ staining}

The Oil Red $\mathrm{O}$ (ORO) staining was according to Amacher et al. [65,66]. Briefly, the cells were washed twice with ice-cold PBS and fixed with 10\% formalin for $1 \mathrm{~h}$, and stained with Oil Red O solution for $2 \mathrm{~h}$ at room temperature. After staining, cells were washed twice with distilled water to remove unbound dye. To quantitate the intracellular lipid content levels, isopropanol was added to each sample shaken at room temperature for $5 \mathrm{~min}$, and samples were read spectrophotometrically at $520 \mathrm{~nm}$.

\section{Triglycerides and cholesterol assay}

For lipidic determinations, homogenates from cells were extracted according to a Heider et al. [67]. Briefly, each sample was homogenized with isopropyl alcohol. The resulting mixture was shaken at room temperature for $1 \mathrm{~h}$ and then centrifuged at $1200 \times \mathrm{g}$ for $10 \mathrm{~min}$. The supernatant was collected for analysis of hepatic TG and TC content. The residue was dissolved in $0.1 \mathrm{M}$ sodium hydroxide and an aliquot was taken for protein determination with an RC DC Protein Assay Kit (Bio-Rad, Hercules, CA, USA). Triacylglycerol and cholesterol were measured using enzymatic method kits (Cell Biolabs, Inc. San Diego, CA, USA) according to the manufacturer's instructions.

\section{Protein extract and sample preparation for 2-DE}

The HepG2 cells were harvested by trypsinization and washed twice with ice-cold PBS buffer. The cells were lysed in lysis buffer (7 M urea, $2 \mathrm{M}$ thiourea, $4 \%$ [w/v] CHAPS, 65 mM DTT, 2\% [v/v] Bio-Lyte pH [3-10], 2\% protease inhibitor cocktail), mixed by vortexing, kept in an ice bath for $2 \mathrm{~h}$, then sonicated in an ice bath. The sample was clarified by centrifugation at $15000 \times \mathrm{g}$ for $1 \mathrm{~h}$ at $4^{\circ} \mathrm{C}$, and the supernatants stored at $-80^{\circ} \mathrm{C}$ until use for 2-DE. Protein content was quantified using the RC DC Protein Assay Kit (Bio-Rad).

\section{2-DE and image analysis}

About $1.3 \mathrm{mg}$ protein dissolved in $350 \mu \mathrm{L}$ rehydration buffer was applied to IPG strips $(17 \mathrm{~cm}, \mathrm{pH} 3-10$, BioRad), which was allowed to rehydrate for $13 \mathrm{~h}$ at $50 \mathrm{~V}$ $\left(20^{\circ} \mathrm{C}\right)$. Subsequently, isoelectric focusing (IEF) was performed at using a Protean IEF Cell (Bio-Rad) under the following conditions: $250 \mathrm{~V}$ for $1 \mathrm{~h}$ with a slow increase in voltage, $500 \mathrm{~V}$ for $1 \mathrm{~h}$ with a slow increase in voltage, $1000 \mathrm{~V}$ for $1 \mathrm{~h}$ with a slow increase in voltage, $10000 \mathrm{~V}$ for $5 \mathrm{~h}$ with a linear increase in voltage, and maintained at $10000 \mathrm{~V}$ until 60000 Volt-hours (Vh) was reached. After IEF, the strips were equilibrated for $15 \mathrm{~min}$ in equilibration buffer I $(0.375 \mathrm{M}$ Tris- $\mathrm{HCl} \mathrm{pH}$ 8.8, $6 \mathrm{M}$ urea, $2 \% \mathrm{SDS}, 20 \%$ glycerol, $1 \% \mathrm{DTT}$ ), then reequilibrated in buffer II containing $2.5 \%$ iodoacetamide instead of DTT for $15 \mathrm{~min}$. The strips were transferred onto $12 \%$ polyacrylamide gels for SDS-PAGE. Electrophoresis was performed using the PROTEAN II xi Cell system (Bio-Rad) at $10 \mathrm{~mA}$ per gel for $30 \mathrm{~min}$, followed by $30 \mathrm{~mA}$ until the bromophenol blue marker reached the end of the gel. Gels were run in triplicate for each sample. The gels were stained with modified colloidal CBB G-250 [68] and were scanned using Quantity One 4.6.9 (Bio-Rad) with a Bio-Rad GS800 scanner. Image and statistical analysis was performed with PDQuest 8.0.1 (Bio-Rad) as previously reported [69]. In the quantitative analysis, 1.5 and 0.5 were chosen as the upper 
and lower limits, respectively. Student's $t$-test and a significance level of $95 \%$ were used for the statistical analysis of the gels. Each sample was performed in triplicate gels.

\section{Protein in-gel digestion and identification}

Protein spots were manually excised from the gel, and digested as previously reported [69]. Mass spectrometric analysis was performed with an Ultraflex MALDI TOF/ TOF mass spectrometer (Bruker Daltonik, Bremen, Germany), under the control of FlexControl ${ }^{\mathrm{TM}} 2.2$ software (Bruker Daltonik GmbH). The TOF spectra were recorded in the positive ion reflector mode in a mass range from $800-4000 \mathrm{Da}$. Ten subspectra with 30 shots per subspectrum were accumulated to generate one main TOF spectrum. After automated assessment of the search results with MASCOT software (Matrix Science, London, UK), the samples not unambiguously identified by PMF were automatically submitted to MS/MS analysis using the LIFT technology in TOF/TOF. A maximum of three strongest peaks of the TOF MS spectrum per sample were chosen for MS/MS analysis. Three subspectra with 50 shots per subspectrum for precursor ions and 15 subspectra with 50 shots per subspectrum for fragment ions were accumulated to produce one main MS/MS spectrum. After the automated analysis, remaining unidentified samples were manually analyzed.

\section{Database searching}

Protein identification from MS/MS sequencing spectra was accomplished using the MASCOT database search engine (Matrix Science, London, UK). The searching parameters were set as follows: taxonomy, Homo sapiens; database, NCBInr/Swiss-Prot; enzyme, trypsin; fixed modifications, carbamidomethyl $(\mathrm{C})$; variable modifications, oxidation $(\mathrm{M})$; no restrictions on protein mass; allow up to one missed cleavages. Mass values, Monoisotopic; Peptide Mass Tolerance was set as \pm 50 ppm; Fragment Mass Tolerance was set as $\pm 0.5 \mathrm{Da}$. Positive protein identification was based on standard MASCOT criteria for statistical analysis of the LC-MS/MS data. The peptide assignments in the database search results were manually inspected for validation.

\section{Western blotting analysis}

The HepG2 cells were harvested by trypsinization and washed twice with ice-cold PBS buffer. The cells were lysed in RIPA buffer (25 mM Tris- $\mathrm{HCl}$ pH 7.6, $150 \mathrm{mM}$ $\mathrm{NaCl}, 1 \%$ NP-40, 1\% sodium deoxycholate, 0.1\% SDS, $2 \%$ protease inhibitor cocktail). Equal amounts of protein were separated on a $12 \%$ SDS-polyacrylamide gel, blotted onto a PVDF membrane, which was blocked for $1 \mathrm{~h}$ at $25^{\circ} \mathrm{C}$ with $5 \% \mathrm{wt} / \mathrm{vol} \mathrm{BSA} / \mathrm{TBST}$ (10 mM Tris $\mathrm{HCl}, \mathrm{pH} 7.4,140 \mathrm{mM} \mathrm{NaCl}, 0.1 \%$ Tween-20) and then incubated with the primary antibody for Prdx6 (1:3000), SDHA (1:1000) and GALK (1:1000) at $4^{\circ} \mathrm{C}$ overnight. After washing with TBST, the membranes were incubated with the appropriate secondary antibodies for $1 \mathrm{~h}$ at $37^{\circ} \mathrm{C}$ and detected by immuno-staining. After the membranes were scanned, the signal intensity of each band was determined using FluorChem FC2 (Alpha Innotech Co., Ltd, San Leandro, CA, USA).

\section{Statistical analysis}

All results were expressed as mean \pm SD and analyzed by student's $t$-test. A $p \leq 0.05$ was considered to be statistically significant.

\section{Abbreviations}

EGCG: (-)-epigallocatechin-3-gallate; 2-DE: Two-dimensional gel electrophoresis; MALDI-TOF/TOF MS: Matrix-assisted laser desorption ionization time-of-flight mass spectrometry; FFA: Free fatty acid; OA: Oleic acid; PA: Palmitic acid; TG: Triglycerides; TC: Cholesterol; AMPK: AMP-activated protein kinase; Prdx6: Peroxiredoxin-6; ROS: Reactive oxygen species; SDH: Succinate dehydrogenase; SDHA: Succinate dehydrogenase flavoprotein subunit; PAFAH: Platelet-activating factor acetylhydrolase; PAF: Platelet-activating factor; PAFAH1B3: Platelet-activating factor acetylhydrolase IB subunit gamma; SBCAD: Short/branched-chain acyl-CoA dehydrogenases; 2MBG: 2-methylbutyrylglycine; GSH: Glutathione; GALK: Galactokinase; PPCA: Lysosomal protective protein; PP-1A: Serine/ threonine protein phosphatase-alpha catalytic subunit; PSP: Phosphoserine phosphatase; FAS: Fatty acid synthase; TORC2: Transducer of regulated CREB activity 2; PHB: Prohibitin.

\section{Competing interests}

The authors declare that they have no competing interest.

\section{Authors' contributions}

ZHL conceived of the study, and participated in all the experiment. QL participated in the 2-DE experiments, mass spectrometry analysis and western blotting analysis. JAH participated in participated in the design of the study. QLL participated in the cell experiments. YJY participated in the 2-DE experiments. HYL participated in western blotting analysis. WJX participated in the critical review of the manuscript. YL participated in the protein identification. SZ participated in the protein identification. BT participated in cell experiments. GAL conceived of the study, and participated in its design and coordination. All authors read and approved the final manuscript.

\section{Acknowledgements}

The work was supported by the Key Project of National Technology Innovation System for Tea Industry in the People's Republic of China (CARS-23), the natural science foundation of Hunan Province (13JJ4067), National Science and Technology Support Program (2012bad33b11), National Natural Science Foundation of China (31100502) and Specialized Research Foundation for the Doctorial Program of Higher Education of China (20114320120004)

\section{Author details}

'Department of Chemistry, Tsinghua University and Key Laboratory of Biological Organic Phosphorus and Chemical Biology, Ministry of Education, Beijing 100084, China. ${ }^{2}$ Hunan Provincial Key Laboratory of Crop Germplasm Innovation and Utilization and Key Laboratory of Tea Science, Ministry of Education, Hunan Agricultural University, Changsha, Hunan 410128, China ${ }^{3}$ National Research Center of Engineering \& Technology for Utilization of Botanical Functional Ingredients, Changsha, Hunan 410128, China.

Received: 25 February 2013 Accepted: 16 July 2013

Published: 18 July 2013 


\section{References}

1. Angulo P, Lindor KD: Non-alcoholic fatty liver disease. J Gastroenterol Hepatol 2002, 17:S186-S190.

2. Suzuki $Y$, Miyoshi N, Isemura M: Health-promoting effects of green tea. Proc Jpn Acad Ser B Phys Biol Sci 2012, 88:88-101.

3. Yang CS, Landau JM: Effects of tea consumption on nutrition and health. J Nutr 2000, 130:2409-2412.

4. Kao YH, Chang HH, Lee MJ, Chen CL: Tea, obesity, and diabetes. Mol Nutr Food Res 2006, 50:188-210.

5. Wolfram S, Wang $Y$, Thielecke F: Anti-obesity effects of green tea: from bedside to bench. Mol Nutr Food Res 2006, 50:176-187.

6. Bose M, Lambert JD, Ju J, Reuhl KR, Shapses SA, Yang CS: The major green Tea polyphenol, (-)-epigallocatechin-3-gallate, inhibits obesity, metabolic syndrome, and fatty liver disease in high-Fat-Fed mice. J Nutr 2008, 138:1677-1683.

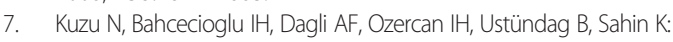
Epigallocatechin gallate attenuates experimental non-alcoholic steatohepatitis induced by high fat diet. J Gastroenterol Hepatol 2008, 23:e465-e470.

8. Chen YK, Cheung C, Reuhl KR, Liu AB, Lee MJ, Lu YP, Yang CS: Effects of green tea polyphenol (-)-epigallocatechin-3-gallate on newly developed high-fat/Western-style diet-induced obesity and metabolic syndrome in mice. J Agric Food Chem 2011, 59:11862-11871.

9. Klaus S, Pultz S, Thone-Reineke C, Wolfram S: Epigallocatechin gallate attenuates diet-induced obesity in mice by decreasing energy absorption and increasing fat oxidation. Int J Obes (Lond) 2005, 29:615-623.

10. Tokimitsu I: Effects of tea catechins on lipid metabolism and body fat accumulation. Biofactors 2004, 22:141-143.

11. Murase T, Haramizu S, Shimotoyodome A, Nagasawa A, Tokimitsu I: Green tea extract improves endurance capacity and increases muscle lipid oxidation in mice. Am J Physiol Regul Integr Comp Physiol 2005, 288:R708-R715.

12. Wolfram S, Raederstorff D, Wang Y, Teixeira SR, Elste V, Weber P: TEAVIGO (epigallocatechin gallate) supplementation prevents obesity in rodents by reducing adipose tissue mass. Ann Nutr Metab 2005, 49:54-63.

13. Brusselmans K, De Schrijver E, Heyns W, Verhoeven G, Swinnen JV: Epigallocatechin-3-gallate is a potent natural inhibitor of fatty acid synthase in intact cells and selectively induces apoptosis in prostate cancer cells. Int J Cancer 2003, 106:856-862.

14. Yeh CW, Chen WJ, Chiang CT, Lin-Shiau SY, Lin JK: Suppression of fatty acid synthase in MCF-7 breast cancer cells by tea and tea polyphenols: a possible mechanism for their hypolipidemic effects. Pharmacogenomics $J$ 2003, 3:267-276

15. Mochizuki M, Hasegawa N: Stereospecific effects of catechin isomers on insulin induced lipogenesis in 3T3-L1 cells. Phytother Res 2004, 18:449-450.

16. Araya J, Rodrigo R, Videla LA, Thielemann L, Orellana M, Pettinelli $P$, Poniachik J: Increase in long-chain polyunsaturated fatty acid $n-6 / n-3$ ratio in relation to hepatic steatosis in patients with non-alcoholic fatty liver disease. Clin Sci (Lond) 2004, 106:635-643.

17. Gómez-Lechón MJ, Donato MT, Martínez-Romero A, Jiménez N, Castell JV, O'Connor J-E: A human hepatocellular in vitro model to investigate steatosis. Chemico-Biol Interact 2007, 165:106-116.

18. Gomez-Lechon MJ, Donato MT, Martinez-Romero A, Jimenez N, Castell JV, O'Connor JE: A human hepatocellular in vitro model to investigate steatosis. Chem Biol Interact 2007, 165:106-116.

19. Marchesini G, Brizi M, Bianchi G, Tomassetti S, Bugianesi E, Lenzi M, McCullough A, Natale S, Forlani G, Melchionda N: Nonalcoholic fatty liver disease: a feature of the metabolic syndrome. Diabetes 2001, 50:1844-1850

20. Musso G, Gambino R, Cassader M: Recent insights into hepatic lipid metabolism in non-alcoholic fatty liver disease (NAFLD). Prog Lipid Res 2009, 48:1-26.

21. Hwang J, Park IJ, Shin JI, Lee YK, Lee SK, Baik HW, Ha J, Park OJ: Genistein, EGCG, and capsaicin inhibit adipocyte differentiation process via activating AMP-activated protein kinase. Biochem Biophys Res Commun 2005, 338:694-699.

22. Moon HS, Chung CS, Lee HG, Kim TG, Choi YJ, Cho CS: Inhibitory effect of (-)-epigallocatechin-3-gallate on lipid accumulation of 3T3-L1 cells. Obesity (Silver Spring) 2007, 15:2571-2582.

23. Wang $\mathrm{CT}$, Chang HH, Hsiao CH, Lee MJ, Ku HC, Hu YJ, Kao YH: The effects of green tea (-)-epigallocatechin-3-gallate on reactive oxygen species in 3T3-L1 preadipocytes and adipocytes depend on the glutathione and 67 kDa laminin receptor pathways. Mol Nutr Food Res 2009, 53:349-360.

24. Hwang J-T, Kwon DY, Yoon SH: AMP-activated protein kinase: a potential target for the diseases prevention by natural occurring polyphenols. New Biotechnol 2009, 26:17-22.
25. Pak JH, Manevich Y, Kim HS, Feinstein SI, Fisher AB: An antisense oligonucleotide to 1-cys peroxiredoxin causes lipid peroxidation and apoptosis in lung epithelial cells. J Biol Chem 2002, 277:49927-49934.

26. Wang Y, Feinstein SI, Fisher AB: Peroxiredoxin 6 as an antioxidant enzyme: protection of lung alveolar epithelial type II cells from H2O2-induced oxidative stress. J Cell Biochem 2008, 104:1274-1285.

27. Emerling BM, Weinberg F, Snyder C, Burgess Z, Mutlu GM, Viollet B, Budinger GRS, Chandel NS: Hypoxic activation of AMPK is dependent on mitochondrial ROS but independent of an increase in AMP/ATP ratio. Free Radic Biol Med 2009, 46:1386-1391.

28. Lin CL, Huang HC, Lin JK: Theaflavins attenuate hepatic lipid accumulation through activating AMPK in human HepG2 cells. J Lipid Res 2007, 48:2334-2343.

29. Carling D, Thornton C, Woods A, Sanders MJ: AMP-activated protein kinase: new regulation, new roles? Biochem J 2012, 445:11-27.

30. Fediuc S, Gaidhu MP, Ceddia RB: Regulation of AMP-activated protein kinase and acetyl-CoA carboxylase phosphorylation by palmitate in skeletal muscle cells. J Lipid Res 2006, 47:412-420.

31. Viollet B, Foretz M, Guigas B, Horman S, Dentin R, Bertrand L, Hue L, Andreelli F: Activation of AMP-activated protein kinase in the liver: a new strategy for the management of metabolic hepatic disorders. J Physiol 2006, 574:41-53.

32. Oyedotun KS, Lemire BD: The quaternary structure of the Saccharomyces cerevisiae succinate dehydrogenase. Homology modeling, cofactor docking, and molecular dynamics simulation studies. J Biol Chem 2004, 279:9424-9431.

33. Rutter J, Winge DR, Schiffman JD: Succinate dehydrogenase - assembly, regulation and role in human disease. Mitochondrion 2010, 10:393-401.

34. Goodpaster BH, He J, Watkins S, Kelley DE: Skeletal muscle lipid content and insulin resistance: evidence for a paradox in endurance-trained athletes. J Clin Endocrinol Metab 2001, 86:5755-5761.

35. Simoneau JA, Veerkamp JH, Turcotte LP, Kelley DE: Markers of capacity to utilize fatty acids in human skeletal muscle: relation to insulin resistance and obesity and effects of weight loss. FASEB J 1999, 13:2051-2060.

36. Sun G, Ukkola O, Rankinen T, Joanisse DR, Bouchard C: Skeletal muscle characteristics predict body fat gain in response to overfeeding in never-obese young men. Metab Clin Exp 2002, 51:451-456.

37. Yechoor VK, Patti ME, Saccone R, Kahn CR: Coordinated patterns of gene expression for substrate and energy metabolism in skeletal muscle of diabetic mice. Proc Natl Acad Sci U S A 2002, 99:10587-10592.

38. Kern PA, Simsolo RB, Fournier M: Effect of weight loss on muscle fiber type, fiber size, capillarity, and succinate dehydrogenase activity in humans. J Clin Endocrinol Metab 1999, 84:4185-4190

39. Menshikova EV, Ritov VB, Ferrell RE, Azuma K, Goodpaster BH, Kelley DE: Characteristics of skeletal muscle mitochondrial biogenesis induced by moderate-intensity exercise and weight loss in obesity. J Appl Physiol 2007, 103:21-27.

40. Stafforini DM, McIntyre TM, Zimmerman GA, Prescott SM: Platelet-activating factor acetylhydrolases. J Biol Chem 1997, 272:17895-17898.

41. Tjoelker LW, Wilder C, Eberhardt C, Stafforini DM, Dietsch G, Schimpf B, Hooper S, Le Trong H, Cousens LS, Zimmerman GA, et al: Anti-inflammatory properties of a platelet-activating factor acetylhydrolase. Nature 1995, 374:549-553.

42. Vittos O, Toana B, Vittos A, Moldoveanu E: Lipoprotein-associated phospholipase A2 (Lp-PLA2): a review of its role and significance as a cardiovascular biomarker. Biomarkers 2012, 17:289-302.

43. Zimmerman GA, McIntyre TM, Prescott SM, Stafforini DM: The plateletactivating factor signaling system and its regulators in syndromes of inflammation and thrombosis. Crit Care Med 2002, 30:S294-S301.

44. Sass JO, Ensenauer R, Roschinger W, Reich H, Steuerwald U, Schirrmacher O, Engel K, Haberle J, Andresen BS, Megarbane A, et al: 2-Methylbutyrylcoenzyme a dehydrogenase deficiency: functional and molecular studies on a defect in isoleucine catabolism. Mol Genet Metab 2008, 93:30-35.

45. Knebel LA, Zanatta A, Tonin AM, Grings M, Alvorcem Lde M, Wajner M, Leipnitz G: 2-Methylbutyrylglycine induces lipid oxidative damage and decreases the antioxidant defenses in rat brain. Brain Res 2012, 1478:74-82.

46. Holden HM, Rayment I, Thoden JB: Structure and function of enzymes of the Leloir pathway for galactose metabolism. J Biol Chem 2003, 278:43885-43888.

47. Novak EM, Lee EK, Innis SM, Keller BO: Identification of novel protein targets regulated by maternal dietary fatty acid composition in neonatal rat liver. J Proteomics 2009, 73:41-49. 
48. Boll M, Löwel M, Berndt J: Effect of unsaturated fatty acids on sterol biosynthesis in yeast. Biochimica et Biophysica Acta (BBA) - Lipids Lipid Metabol 1980, 620:429-439.

49. Galjart NJ, Morreau H, Willemsen R, Gillemans N, Bonten EJ, D'Azzo A: Human lysosomal protective protein has cathepsin a-like activity distinct from its protective function. J Biol Chem 1991, 266:14754-14762.

50. Wera S, Hemmings BA: Serine/threonine protein phosphatases. Biochem J 1995, 311(Pt 1):17-29.

51. Foretz M, Carling D, Guichard C, Ferre P, Foufelle F: AMP-activated protein kinase inhibits the glucose-activated expression of fatty acid synthase gene in rat hepatocytes. J Biol Chem 1998, 273:14767-14771.

52. Fu H, Subramanian RR, Masters SC: 14-3-3 proteins: structure, function, and regulation. Annu Rev Pharmacol Toxicol 2000, 40:617-647.

53. Mhawech P: 14-3-3 proteins-an update. Cell Res 2005, 15:228-236.

54. Koo SH, Flechner L, Qi L, Zhang X, Screaton RA, Jeffries S, Hedrick S, Xu W, Boussouar F, Brindle $P$, et al: The CREB coactivator TORC2 is a key regulator of fasting glucose metabolism. Nature 2005, 437:1109-1111.

55. Viollet B, Guigas B, Leclerc J, Hébrard S, Lantier L, Mounier R, Andreelli F, Foretz M: AMP-activated protein kinase in the regulation of hepatic energy metabolism: from physiology to therapeutic perspectives. Acta Physiologica 2009, 196:81-98.

56. Wada T, Kenmochi H, Miyashita Y, Sasaki M, Ojima M, Sasahara M, Koya D, Tsuneki H, Sasaoka T: Spironolactone improves glucose and lipid metabolism by ameliorating hepatic steatosis and inflammation and suppressing enhanced gluconeogenesis induced by high-fat and highfructose diet. Endocrinology 2010, 151:2040-2049.

57. McClung JK, Jupe ER, Liu XT, Dell'Orco RT: Prohibitin: potential role in senescence, development, and tumor suppression. Exp Gerontol 1995, 30:99-124.

58. Mishra S, Murphy LC, Nyomba BL, Murphy LJ: Prohibitin: a potential target for new therapeutics. Trends Mol Med 2005, 11:192-197.

59. Vessal M, Mishra S, Moulik S, Murphy LJ: Prohibitin attenuates insulinstimulated glucose and fatty acid oxidation in adipose tissue by inhibition of pyruvate carboxylase. FEBS J 2006, 273:568-576.

60. Burton GR, Nagarajan R, Peterson CA, McGehee RE Jr: Microarray analysis of differentiation-specific gene expression during 3T3-L1 adipogenesis. Gene 2004, 329:167-185.

61. Artal-Sanz M, Tavernarakis N: Prohibitin couples diapause signalling to mitochondrial metabolism during ageing in C. elegans. Nature 2009, 461:793-797.

62. Wu X, Zhang L, Gurley E, Studer E, Shang J, Wang T, Wang C, Yan M, Jiang $Z$, Hylemon PB, et al: Prevention of free fatty acid-induced hepatic lipotoxicity by 18 beta-glycyrrhetinic acid through lysosomal and mitochondrial pathways. Hepatology 2008, 47:1905-1915.

63. Cousin SP, Hugl SR, Wrede CE, Kajio H, Myers MG Jr, Rhodes CJ: Free fatty acid-induced inhibition of glucose and insulin-like growth factor Iinduced deoxyribonucleic acid synthesis in the pancreatic beta-cell line INS-1. Endocrinology 2001, 142:229-240.

64. Kuo C-F, Hsieh C-H, Lin W-Y: Proteomic response of LAP-activated RAW 264.7 macrophages to the anti-inflammatory property of fungal ergosterol. Food Chem 2011, 126:207-212.

65. Ramirez-Zacarias JL, Castro-Munozledo F, Kuri-Harcuch W: Quantitation of adipose conversion and triglycerides by staining intracytoplasmic lipids with Oil red O. Histochemistry 1992, 97:493-497.

66. Amacher DE, Martin BA: Tetracycline-induced steatosis in primary canine hepatocyte cultures. Fundam App/ Toxicol 1997, 40:256-263.

67. Heider JG, Boyett RL: The picomole determination of free and total cholesterol in cells in culture. J Lipid Res 1978, 19:514-518.

68. Candiano G, Bruschi M, Musante L, Santucci L, Ghiggeri GM, Carnemolla B, Orecchia P, Zardi L, Righetti PG: Blue silver: a very sensitive colloidal Coomassie G-250 staining for proteome analysis. Electrophoresis 2004, 25:1327-1333.

69. Li Q, Huang J, Liu S, Li J, Yang X, Liu Y, Liu Z: Proteomic analysis of young leaves at three developmental stages in an albino tea cultivar. Proteome Sci 2011, 9:44.

doi:10.1186/1477-5956-11-32

Cite this article as: Liu et al:: Proteomic analysis of the inhibitory effect of epigallocatechin gallate on lipid accumulation in human HepG2 cells. Proteome Science 2013 11:32.

\section{Submit your next manuscript to BioMed Central and take full advantage of:}

- Convenient online submission

- Thorough peer review

- No space constraints or color figure charges

- Immediate publication on acceptance

- Inclusion in PubMed, CAS, Scopus and Google Scholar

- Research which is freely available for redistribution 